\title{
MODELLING OF POLLEN DISPERSION IN THE ATMOSPHERE: EVALUATION WITH A CONTINUOUS $1 \beta+1 \delta$ LIDAR
}

\author{
Michaël Sicard ${ }^{* 1,2}$, Rebeca Izquierdo ${ }^{3,4,5}$, Oriol Jorba ${ }^{6}$, Marta Alarcón ${ }^{3}$, Jordina Belmonte ${ }^{4,5}$, Adolfo \\ Comerón $^{1}$, Concepción De Linares ${ }^{4,5}$, José Maria Baldasano ${ }^{7}$ \\ ${ }^{1}$ Remote Sensing Laboratory, Universitat Politècnica de Catalunya, Barcelona, Spain, "Email: \\ msicard@tsc.upc.edu \\ ${ }^{2}$ Ciències i Tecnologies de l'Espai - Centre de Recerca de l'Aeronàutica i de l'Espai / Institut d'Estudis \\ Espacials de Catalunya (CTE-CRAE / IEEC), Universitat Politècnica de Catalunya, Barcelona, Spain \\ ${ }^{3}$ Departament de Física, Universitat Politècnica de Catalunya, Barcelona, Spain \\ ${ }^{4}$ Departament de Biologia Animal, Biologia Vegetal i Ecologia, Universitat Autònoma de Barcelona, \\ Bellaterra, Spain \\ ${ }^{5}$ Institut de Ciencia i Tecnología Ambientals (ICTA), Universitat Autònoma de Barcelona, Bellaterra, \\ Spain \\ ${ }^{6}$ Earth Sciences Department, Barcelona Supercomputing Center - Centro Nacional de \\ Supercomputación, Barcelona, Spain \\ ${ }^{7}$ Environmental Modeling Laboratory, Technical University of Catalonia, Barcelona, Spain
}

\begin{abstract}
Pollen allergenicity plays an important role on human health and wellness. It is thus of large public interest to increase our knowledge of pollen grain behavior in the atmosphere (source, emission, processes involved during their transport, etc.) at fine temporal and spatial scales. First simulations with the Barcelona Supercomputing Center NMMB/BSC-CTM model of Platanus and Pinus dispersion in the atmosphere were performed during a 5-day pollination event observed in Barcelona, Spain, between 27 - 31 March, 2015. The simulations are compared to vertical profiles measured with the continuous Barcelona Micro Pulse Lidar system. First results show that the vertical distribution is well reproduced by the model in shape, but not in intensity, the model largely underestimating in the afternoon. Guidelines are proposed to improve the dispersion of airborne pollen by numerical prediction models.
\end{abstract}

\section{INTRODUCTION}

Respirable allergenic materials such as pollen grains are a serious public health concern worldwide with the most prevalent impacts among children and adolescents [1][2]. Allergic airway diseases may increase further in the future due to intensive human activities that perturb the environment and change land management practices, which could modify the pollen amount, pollen allergenicity, duration of pollen season, and pollen spatial distributions [3][4].

Several numerical models have been used to simulate the dispersion of pollen in the atmosphere in Europe [5][6] and in the United States [7]. Most of these simulations are confined to short-term pollination events affecting a rather small region and restricted to just a few pollen types. While the evaluation of these simulations is almost always performed against in-situ pollen concentration measurements, nearly no information is known about their performance in the atmospheric column. In Europe, only the SILAM (System for Integrated modeLling of Atmospheric composition [6]) model from the Finnish Meteorological Institute is providing forecast of pollen grain number concentration at continental scale, but without performing routine evaluation.

This work presents the very first simulations with the Nonhydrostatic Multiscale Meteorological Model on the B grid at the Barcelona Supercomputing Center (BSC) with a newly developed Chemical Transport Model (NMMB/BSC-CTM) of the dispersion of Platanus and Pinus pollen in the atmosphere which occurred during a 5-day pollination event in Barcelona, Spain, between 27 - 31 March, 2015. The model evaluation in the atmospheric 
column is performed against continuous lidar measurements. The results are discussed in terms of the pollen parametrization and the schemes used in the model.

\section{INSTRUMENTS AND MODELLING}

\subsection{Pollen measurements}

During the event considered here, the daily and hourly concentration of 93 types of pollen was measured from pollen samples obtained using volumetric suction pollen trap based on the impact principle, the standardized method in European aerobiological networks. Further details on the instrument and method can be found in [8][9].

Measurements of the vertical distribution of the particle backscatter coefficient and of the volume and particle depolarization ratios were made with the Barcelona Micro Pulse Lidar (MPL) system, Sigma Space model MPL-4B, part of the MPLNET (Micro Pulse Lidar Network, http://mplnet.gsfc.nasa.gov/) network. The Barcelona MPL optical layout uses an actively controlled liquid crystal retarder which makes the system capable to conduct polarization-sensitive measurements by alternating between two retardation states [10]. The signals, called "copolar", $P_{c o}$, and "cross-polar", $P_{c r}$, are used to calculate the total signal, $P$, as $P=P_{c o}+2 P_{c r}$, which is inverted using the two-component elastic lidar inversion and a constant lidar ratio, $L R$, of $50 \mathrm{sr}$ to obtain the particle backscatter coefficient. $P_{c o}$ and $P_{c r}$ are also used to calculate the volume depolarization ratio, $\delta^{V}$, as:

$$
\delta^{V}(z)=\frac{P_{c r}(z)}{P_{c o}(z)+P_{c r}(z)}
$$

Pollen has formerly been distinguished from other particle types thanks to its depolarization capabilities (see references in [8]). For this reason the particle depolarization ratio is also calculated using Eq. (4) of [8]. To quantify the pollen contribution to the particle backscatter ratio the method of [11] is used assuming that the external mixing of particles observed is composed only of depolarizing (pollen) and much less depolarizing (everything but pollen) particles. The pollen backscatter coefficient, $\beta_{\text {pol }}^{o b s}$, is then calculated using Eqs. (7) and (8) of [8]. The vertical height, $h_{p o l}$, up to which the pollen plume extends is calculated with a simple threshold method [8].

\subsection{Pollen modelling}

The NMMB/BSC-CTM model is the online air quality forecast system developed at BSC [12][13]. Meteorology, transport schemes and the output configuration are the same as in [9].

The two pollen types largely predominant during the pollination event were Pinus and Platanus [8]. Pinus is an important genus of the Spanish landscapes; Platanus is an ornamental tree very common in the street of metropolitan areas. They are selected in this study due to their high airborne pollen concentrations. For this reason the aerosol scheme is set to bulk Pinus and Platanus aerosols. The main parameters, reported in Table 1 , are taken from the literature. Geographical distributions are obtained from the Cartography of habitats of Catalonia for Pinus and from the Barcelona's City Council Open Data Service for Platanus. Pinus tree density, 650 tree/ha, is from the Forest Inventory of Catalonia while for Platanus the number of tree per pixel is directly entered in the model.

Table 1 Pollen parametrization of the aerosol scheme

\begin{tabular}{|l|l|l|}
\hline & Pinus & Platanus \\
\hline Emission & $81 \mathrm{~g} /$ day/tree & $2.48 \mathrm{~g} /$ day/tree \\
factor & {$[14]$} & {$[15]$} \\
\hline Grain diameter & $59 \mu \mathrm{m} \mathrm{[16]}$ & $19 \mu \mathrm{m} \mathrm{[7]}$ \\
\hline Grain density & $560 \mathrm{~kg} / \mathrm{m}^{3}[16]$ & $920 \mathrm{~kg} / \mathrm{m}^{3}[7]$ \\
\hline
\end{tabular}

\section{EVALUATION OF THE FIRST SIMULATIONS}

The pollen simulations are performed at fine temporal (1 hour) and spatial $\left(1 \times 1 \mathrm{~km}^{2}\right)$ scales. The pollen concentration, $C_{\text {pol }}^{\text {mod }}$ in $\mathrm{kg} / \mathrm{m}^{3}$, is calculated at the coordinates of the measurement through a bilinear interpolation and converted to pollen backscatter coefficient as:

$$
\beta_{\text {pol }}^{\mathrm{mod}}=\frac{C_{p o l}^{\mathrm{mod}} \times 10^{3} \times \sigma^{*}}{L R} * 10^{6}\left[\mathrm{Mm}^{-1} \mathrm{sr}^{-1}\right]
$$

where $\sigma^{*}$ is the specific extinction cross-section at $532 \mathrm{~nm}$ in $\mathrm{m}^{2} / \mathrm{g}$. In a first approximation a value of $0.6 \mathrm{~m}^{2} / \mathrm{g}$, taken from [17] and measured for Saharan dust particles, is used. For the 2 days of the event with no (or low) nocturnal pollen 
near-surface activity (27 and 29 March, respectively noted $27 \mathrm{M}$ and $29 \mathrm{M}$, see [8]), Figure 1 shows the comparison model-observation of the daily averaged pollen backscatter coefficient, the hourly difference $\beta_{p o l}^{\text {mod }}-\beta_{p o l}^{o b s}$ and the score of the model in terms of fractional bias and correlation coefficient calculated from the minimum height up to $h_{p o l}$.
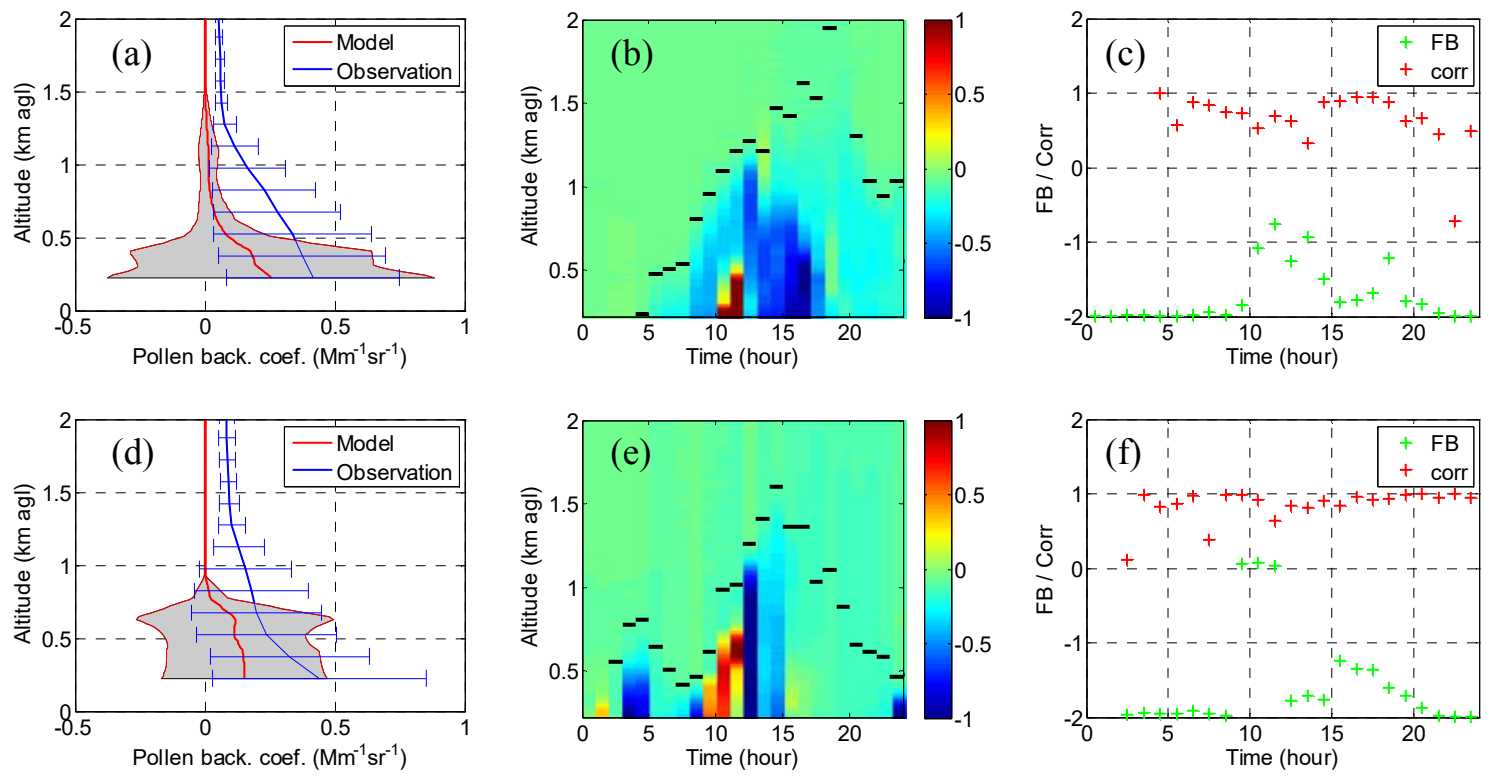

Figure 1 Daily averaged pollen backscatter coefficient ( \pm standard deviation) on (a) 27M and (d) 29M; Hourly difference $\beta_{p o l}^{\text {mod }}-\beta_{p o l}^{o b s}\left(M^{-1} s^{-1}\right)$ on (b) $27 M$ and (e) $29 M$ ( $h_{p o l}$ is reported by horizontal black dashes); Hourly fraction bias (FB) and correlation coefficient (corr) on (c) 27M and (f) $29 M$

A first result is the good performance of the model to reproduce the shape of vertical profiles ( corr $>0.5$ in general). Although the daily averaged $\beta_{p o l}^{\text {mod }}$ falls in both cases in the standard deviation of $\beta_{p o l}^{o b s}$, it appears largely underestimated at all heights. The temporal evolution of their hourly difference shows that the strongest underestimations occur in the afternoon. On both days some overestimations are also visible around 10:00 and below $0.75 \mathrm{~km}$. On $29 \mathrm{M}$ this overestimation is compensated $(F B \simeq 0)$ by the underestimation of the model above $0.75 \mathrm{~km}$. During the night on $29 \mathrm{M}$ (before 06:00) the pollen layers observed $<0.8 \mathrm{~km}$ are not reproduced at all by the model. Several research lines are contemplated to improve these first simulations: (i) complete the tree distribution, (ii) improve the emission scheme and make it time-dependent, (iii) study the sensitivity of the model to pollen size, (iv) identify the mechanisms responsible for the pollen transport during nighttime, (v) study the impact of the changes sea-land $\leftrightarrow$ land-sea breeze regimes on the concentration at the ground and in the atmospheric column.

\section{ACKNOWLEDGEMENTS}

Lidar data analysis were supported by the ACTRIS (Aerosols, Clouds, and Trace Gases Research Infrastructure Network) Research Infrastructure Project funded by the European Union's Horizon 2020 research and innovation programme under grant agreement n. 654169; by the Spanish Ministry of Economy and Competitivity (project TEC2015-63832-P) and of Science and Innovation (project UNPC10-4E-442) and EFRD (European Fund for Regional Development); by the Department of Economy and Knowledge of the Catalan autonomous government (grant 2014 SGR 583). This work is contributing to the ICTA 'Unit of Excellence' (Spanish Ministry of Economy and Competitivity, project MDM2015-0552). 


\section{References}

[1] Nathan, R., Meltzer, E., Selner, J., and Storms, W.: Prevalence of allergenic rhinitis in the United States, J. Allergy Clin. Imm., 99, 808814, 1997.

[2] WHO (World Health Organization), Phenology and human health: allergic disorders, Copenhagen, WHO Regional Office for Europe, 55 pp., 2003.

[3] Beggs, P. J.: Impacts of climate change on aeroallergens: past and future, Clin. Exp. Allergy, 34, 1507-1513, 2004.

[4] D’Amato, G., Cecchi, L., Bonini, S., Nunes, C., Annesi-Maesano, I., Behrendt, H., Liccardi, G., Popov, T., and van Cauwenber, P.: Allergenic pollen and pollen allergy in Europe, Allergy, 62, 976-990, 2007.

[5] Veriankanité, L., Siljamo, P., Sofiev, M., Šauliene, I., and Kukkonen, J.: Modeling analysis of source regions of long-range transported birch pollen that influences allergenic seasons in Lithuania, Aerobiologia, 26, 47-62, 2010.

[6] Sofiev, M., Siljamo, P., Ranta, H., Linkosalo, T., Jaeger, S., Rasmussen, A., RantioLehtimäki, A., Severova, E., and Kukkonen, J.: A numerical model of birch pollen emission and dispersion in the atmosphere. Description of the emission module, Int. J. Biometeorol., 57, 45-58, doi: 10.1007/s00484-012-0532-z, 2013.

[7] Zhang, R., Duhl, T., Salam, M.T., House, J.M., Flagan, R. C., Avol, E.L., Gilliland, F.D., Guenther, A., Chung, S. H., Lamb, B.K., and VanReken, T.M., Development of a regionalscale pollen emission and transport modeling framework for investigating the impact of climate change on allergic airway disease, Biogeosciences 11, 1461-1478, doi:10.5194/bg-11-1461-2014, 2014.

[8] M. Sicard, R. Izquierdo, M. Alarcón, J. Belmonte, A. Comerón, J. M. Baldasano, Nearsurface and columnar measurements with a micro pulse lidar of atmospheric pollen in Barcelona, Spain, Atmospheric Chemistry and Physics, vol. 16, issue 11, pp. 6805-6821, doi: 10.5194/acp-16-6805-2016, 2016.

[9] M. Sicard, R. Izquierdo, O. Jorba, M. Alarcón, J. Belmonte, A. Comerón, J. M. Baldasano, Atmospheric dispersion of airborne pollen evidenced by near-surface and columnar measurements in Barcelona, Spain, Proc. SPIE 10001, 100010L, A. Comerón, E. I. Kassianov, K. Schäfer, J. W. Jack, R. H. Picard, K. Weber (Ed.), SPIE, Washington (EE.UU.), doi: 10.1117/12.2244517, Edinburgh, United Kingdom, 26 - 29 September 2016.

[10] Flynn, C. J., Mendoza, A., Zheng, Y., and Mathur, S., "Novel polarization-sensitive micropulse lidar measurement technique", Optics Express 15(6), 2785-2790 (2007).

[11] Shimizu, A., Sugimoto, N., Matsui, I., Arao, K., Uno, I., Murayama, T., Kagawa, N., Aoki, K., Uchiyama, A., and Yamazaki, A.: Continuous observations of Asian dust and other aerosols by polarization lidars in China and Japan during ACE-Asia, J. Geophys. Res., 109, D19S17, doi: 10.1029/2002JD003253, 2004.

[12] Pérez, C., Haustein, K., Janjic, Z., Jorba, O., Huneeus, N., Baldasano, J. M., Black, T., Basart, S., Nickovic, S., and Miller, R.L., "Atmospheric dust modeling from meso to global scales with the online NMMB/BSC-Dust model - Part 1: Model description, annual simulations and evaluation", Atmospheric Chemistry and Physics 11, 13001-13027 (2011).

[13] Jorba, O., Dabdub, D., Blaszczak-Boxe, C., Pérez, C., Janjic, Z., Baldasano, J. M., Spada, M., Badia, A., and Gonçalves, M., "Potential significance of photoexcited $\mathrm{NO} 2$ on global air quality with the NMMB/BSC chemical transport model", Journal of Geophysical Research 117(D13301), 1-16 (2012).

[14] Williams, C.G., "Conifer reproductive biology. Springer", New York, 167 pp. (2009).

[15] Bricchi, E., Frenguelli, G., Mincigrucci, G., "Experimental results about Platanus pollen deposition", Aerobiologia 16, 347-352 (2000).

[16] Jackson, S.T., and Lyford, M.E., "Pollen Dispersal Models in Quaternary Plant Ecology: Assumptions, Parameters, and Prescriptions", The Botanical Review 65(1), 39-75 (1999).

[17] Pérez, C., Nickovic, S., Baldasano, J. M., Sicard, M., Rocadenbosch, F., and Cachorro, V. E.: A long Saharan dust event over the western Mediterranean: Lidar, sun photometer observations, and regional dust modeling, J. Geophys. Res., 111, D15214, doi:10.1029/2005JD006579, 2006. 